\title{
Establishing a reference rock site for the site effect study in and around the Kathmandu valley, Nepal
}

\author{
Mukunda Bhattarai ${ }^{*}$, Lok Bijaya Adhikari ${ }^{1}$, Umesh Prasad Gautam ${ }^{1}$, Laurent Bollinger ${ }^{2}$, Bruno Hernandez ${ }^{2}$, \\ Toshiaki Yokoi ${ }^{3}$ and Takumi Hayashida ${ }^{3}$
}

\begin{abstract}
We propose a reference site for the site effect study in and around the Kathmandu valley, Nepal. The used data were the accelerograms recorded at two stations, DMG and KKA, and velocity seismograms co-recorded at the PKIN station during nine shallow local and regional earthquakes of local magnitude equal to or greater than 5.0. The DMG station is located on the thick sediments of the Kathmandu valley, whereas the others are rock sites. The KKA station is located on the granite and gneisses of the Shivapuri Lekh about $10 \mathrm{~km}$ northwest of the capital, and the PKIN station is in the tunnel of an old iron mine on the southern slope of the Phulchauki Hill about $15 \mathrm{~km}$ southeast. The spectral ratios of the ground motion records of the DMG station compared to those of the PKIN station, for all considered earthquakes, confirm that the DMG station has amplification ranging from 1 to 10 in the frequency range of 0.5$10 \mathrm{~Hz}$, and spectral ratios of the KKA station referenced by the PKIN station show that the KKA station has significant amplification in the frequency range of $4-10 \mathrm{~Hz}$ and the peak value of the spectral ratio is at most over 25 . Therefore, the site amplification in and around Kathmandu valley would be significantly underestimated in the frequency range from 4 to $10 \mathrm{~Hz}$ if the records of the KKA station were used as a proxy for input seismic motions to the sediment. Based on the above analysis, we propose that the PKIN station should be considered as a reliable reference site for the assessment of seismic hazards in and around the Kathmandu valley.
\end{abstract}

Keywords: Reference site, Site effect, Kathmandu valley, Spectral ratio

\section{Introduction}

Kathmandu, the capital city of Nepal, as well as its sister cities, were established in a fluvio-lacustrine valley at the foot of the high Himalayan range, one of the most active and the highest mountain range of the world (Fig. 1). The valley is severely impacted by large earthquakes due to the very high tectonic activity of the nearby faults as well as the faults that contribute to the growth of the mountain range. The local sites conditions in the valley have large effects on the ground motion at the surface. Therefore, the disaster mitigation from damaging earthquakes is a major concern for the approximately 2.6 million

\footnotetext{
*Correspondence: mb2058@yahoo.com

${ }^{1}$ National Seismological Center, Department of Mines and Geology, Kathmandu, Nepal

Full list of author information is available at the end of the article
}

people who live there. The use of actual strong ground motion records is a crucial component for seismic hazard assessment since the records provide information of local site effect that plays a major role in seismic ground motion and its influences, i.e., damages caused by large earthquakes.

The Kathmandu valley is a tectonic basin formed by the uplift of the Himalayan frontal range and filled by thick lacustrine, alluvial fan and fluvial deposits of the paleoKathmandu lake in Pleistocene and Quaternary that overlay meta-sedimentary Precambrian-Paleozoic bedrock (e.g., Yoshida and Igarashi 1984; Sakai 2001; Sakai et al. 2006; Piya 2004). Moribayasi and Maruo (1980) mapped the basement topography based on their result of gravity survey and estimated the depth of sediment about $650 \mathrm{~m}$ at the deepest point. The depth at the strong motion observation station DMG that is located in the main 


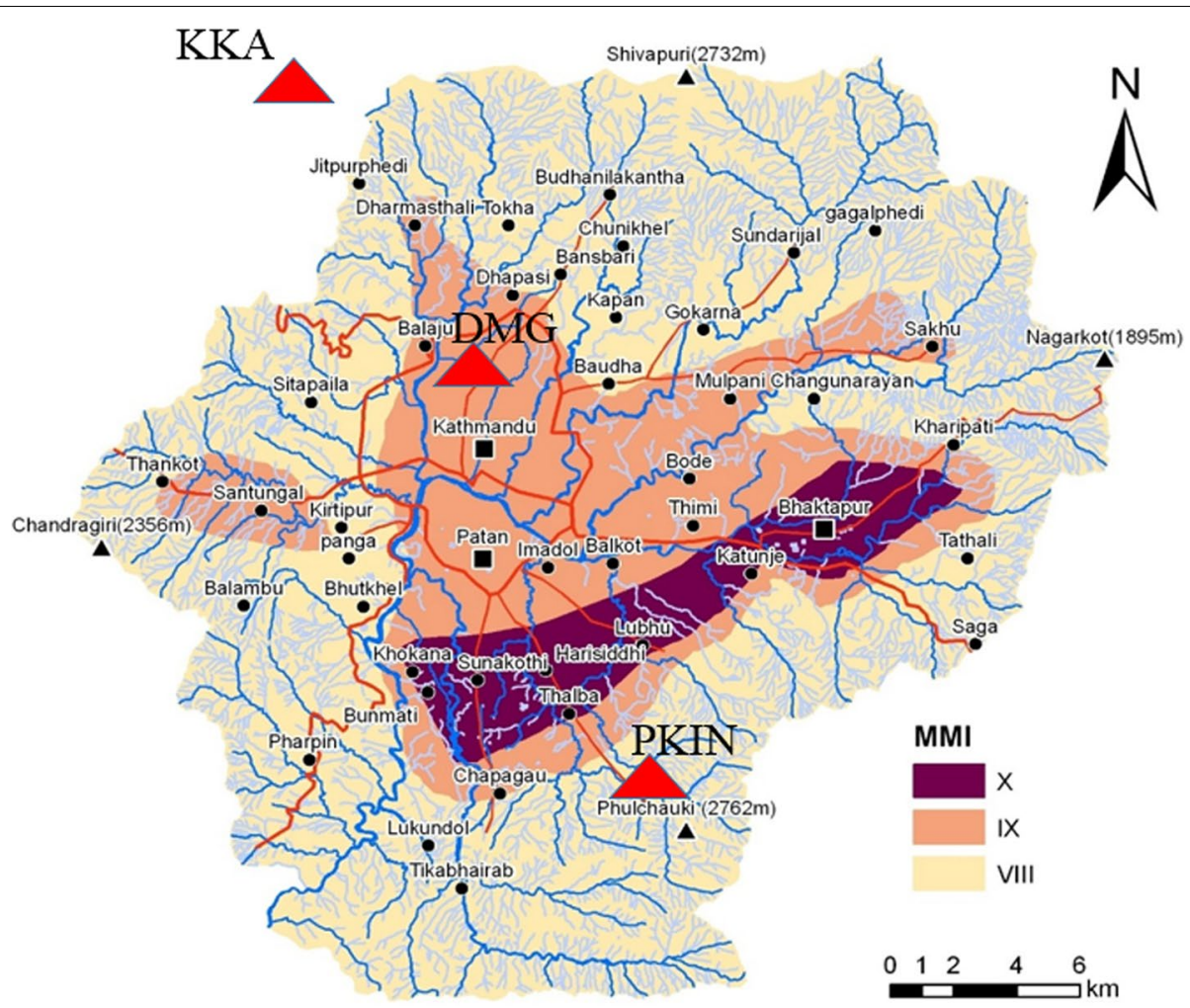

Fig. 1 Location map of the stations in the background of intensity map of 1934 Bihar-Nepal earthquake in the Kathmandu valley [redrawn from Roy et al. (1939) based on the description in Rana et al. (1935) and the stations used in this study are added by the corresponding author]

office building of the Department of Mines and Geology, the Government of Nepal (Fig. 1), is estimated $500 \mathrm{~m}$ that is consistent with the information obtained by drillings nearby (Sakai 2001). In the valley, the average shearwave velocity over the upper $30 \mathrm{~m}$ is spread from 180 to $310 \mathrm{~m} / \mathrm{s}$ (Japan International Cooperation Agency 2002). Paudyal et al. (2012) gave the predominant period of the ground estimated by the horizontal to vertical spectral ratios of ambient noise (so-called Nakamura's method, Nakamura 1989) at the DMG station between 0.5 and $1 \mathrm{~Hz}$ among their 171 measuring points. The intensity distribution during the 1934 Nepal-Bihar earthquake suggests that the underground structure in the valley is not simple (Fig. 1). During the 2015 Gorkha, Nepal earthquake (e.g., Kobayashi et al. 2015; Kubo et al. 2016) clear predominant period around $0.2 \mathrm{~Hz}$ was observed at the DMG station (Bhattarai et al. 2015), in KATNP site maintained by USGS (Dixit et al. 2015) and also in some temporary stations in Kathmandu valley (Takai et al. 2016). These show necessity of further studies by geological and geophysical survey and strong motion and earthquake observations, especially on underground velocity structure and on the shape of hard bedrock that shall be used for seismic hazard assessment.
In Nepal the permanent seismic network has been established under the technical cooperation between Departement Analyse Surveillance de l'Environnement (DASE), Commissariat Energie Atomique (CEA), the Government of France and Department of Mines and Geology, the Government of Nepal since 1978. Within the cooperation, the National Seismological Centre of Department of Mines and Geology (NSC-DMG) has been jointly working with DASE since 2009 in deploying accelerographs in order to study the strong ground motion and its variability in different site conditions, at the DMG station in the central part of the Kathmandu valley (hereafter simply called DMG) as well as six stations at sites comprising among them major cities of Nepal like Pokhara (PKR) and Surkhet (SKT) or co-located with velocimetric stations Ghanteshwore (GHA), Kakani (KKA) and Taplejung (TAP). The first sites to be installed were at DMG, KKA and PKR, and then the network was extended to SKT and Dhunche (DHU) in 2011. After the TaplejungSikkim earthquake in 2011, three temporary stations were deployed in Illam (ILM), TAP and Tumlingtar (TUM) in eastern Nepal. The Taplejung temporary station was later converted to a permanent station. The Dadeldhura (DDR) station in far-western Nepal was moved to GHA. 
NSC-DMG had maintained only two accelerographs, i.e., DMG and KKA, in and around Kathmandu valley before 2014, and KKA would have been considered as a reference site. Bhattarai et al. (2011), however, have pointed out the problem that in the frequency range $4-10 \mathrm{~Hz}$ there was significant amplification at the rock site KKA located on Shivapuri Lekh in comparison with the soil-site DMG on thick fluvio-lacustrine sediments using 2010/10/17 Xizang earthquake (i.e., event No. 1 in Table 1). Then, the appropriateness of KKA as a reference rock site is left in doubt.

Selection of a reliable reference site is a base for studies of the site effects including basin as well as basin-edge effects and then shall be completed with the highest priority. Therefore, this study is aimed to propose a more reliable reference rock site that shall be used for site effect study in and around the Kathmandu valley.

\section{Methods}

One of the experimental indicators that are commonly used to determine site effects at the arbitrary site is $H / H_{\text {ref }}$ spectral ratio (Borcherdt 1970). It is defined as the ratio of the Fourier amplitude spectra of horizontal components of a soil-site record (site of interest) to that of the rock site (reference site) record from the same earthquake. This technique has been applied for practical use, on the assumption that ground motion at the rock site is equivalent to the input motion on the basin bedrock. The $H / H_{\text {ref }}$ ratio is thus the representative of the transfer function of the sedimentary layers at soil site. This is valid only if the difference of source radiation and propagation effects between the two sites can be neglected. It is also necessary to let the distance between source and stations must be sufficiently large compared with the distance between the sites. Since S-waves are very sensitive to site conditions and are the origin of most of the damages, this technique is generally applied to $\mathrm{S}$-waves. This method requires finding a good reference site (Steidl et al. 1996). The specific procedure is described in the next section.

\section{Data and analysis}

In addition to the two accelerographs (i.e., DMG and KKA) maintained by NSC-DMG, we used the velocity waveform data from the station situated to the southeast of Kathmandu in the Phulchauki tunnel (PKIN, see Fig. 1). Altogether we used the digital waveform data obtained during nine earthquakes of different magnitudes equal to or larger than 5.0 recorded at three stations, simultaneously. It is noticed that in some accelerograms P-phase and others the later part of S-phase was missing due to the choice of insufficient pre- and post-event windows in the setup of the instrument. It is also found that some of the velocity seismograms at PKIN were saturated due to the limited dynamic range of the sensor and some breakage occurs before and after P- or S-phase onset in some components. For the selection of earthquakes epicentral distance from DMG located in the capital larger than $60 \mathrm{~km}$ were taken into consideration to prevent the influence of the difference in radiation and propagation effects between the used stations. Therefore, we could use a limited number of the records as shown in Table 1. Signal-to-noise ratio $(S / N)$ of the available records is above two consequently. The epicenter, magnitude and location of the earthquakes and stations of them are shown in Fig. 2. For the convenience, the earthquakes are numbered as shown in Table 1.

The detail of the instruments and condition of sites are summarized in Table 2. PKIN has a short period velocity seismograph of which natural frequency is $1 \mathrm{~Hz}$. Its velocity records are converted to accelerograms by differentiation in the time domain, and the instrumental correction is applied in the frequency domain as described below. Therefore, a careful consideration is required on $S / N$ in the frequency range lower than $1 \mathrm{~Hz}$, especially in the case of weak ground motion.

The strong motion seismographs in DMG and KKA Geo-SIG AC23 have accelerometers that are not the force balanced type. This accelerometer is based on a geophone

Table 1 Parameters of the earthquakes used in this study

\begin{tabular}{|c|c|c|c|c|c|c|}
\hline Event ID & Date (UTC) & Time (UTC) & Latitude & Longitude & $\begin{array}{l}D_{\text {epi }} \text { from } \\
\text { DMG (km) }\end{array}$ & NSC magnitude $\left(M_{L}\right)$ \\
\hline 1 & 20101017 & $20: 11: 22$ & 28.64 & 85.71 & 110.55 & 5.7 \\
\hline 2 & 20101018 & $04: 26: 55$ & 28.65 & 85.73 & 112.5 & 5.2 \\
\hline 3 & 20110815 & $16: 48: 07$ & 27.44 & 86.27 & 100.13 & 5.0 \\
\hline 4 & 20110918 & $12: 40: 50$ & 27.71 & 88.30 & 296.23 & 6.8 \\
\hline 5 & 20111112 & $23: 46: 57$ & 28.18 & 84.93 & 63.63 & 5.3 \\
\hline 6 & 20130628 & $11: 40: 56$ & 28.47 & 82.67 & 272.74 & 5.5 \\
\hline 7 & 20130715 & $19: 39: 45$ & 28.75 & 87.59 & 252.99 & 5.6 \\
\hline 8 & 20130830 & $17: 48: 43$ & 28.43 & 86.02 & 106.17 & 6.1 \\
\hline 9 & 20130830 & $18: 02: 30$ & 28.48 & 86.03 & 111.27 & 5.2 \\
\hline
\end{tabular}

$D_{e p i}$ epicentral distance 


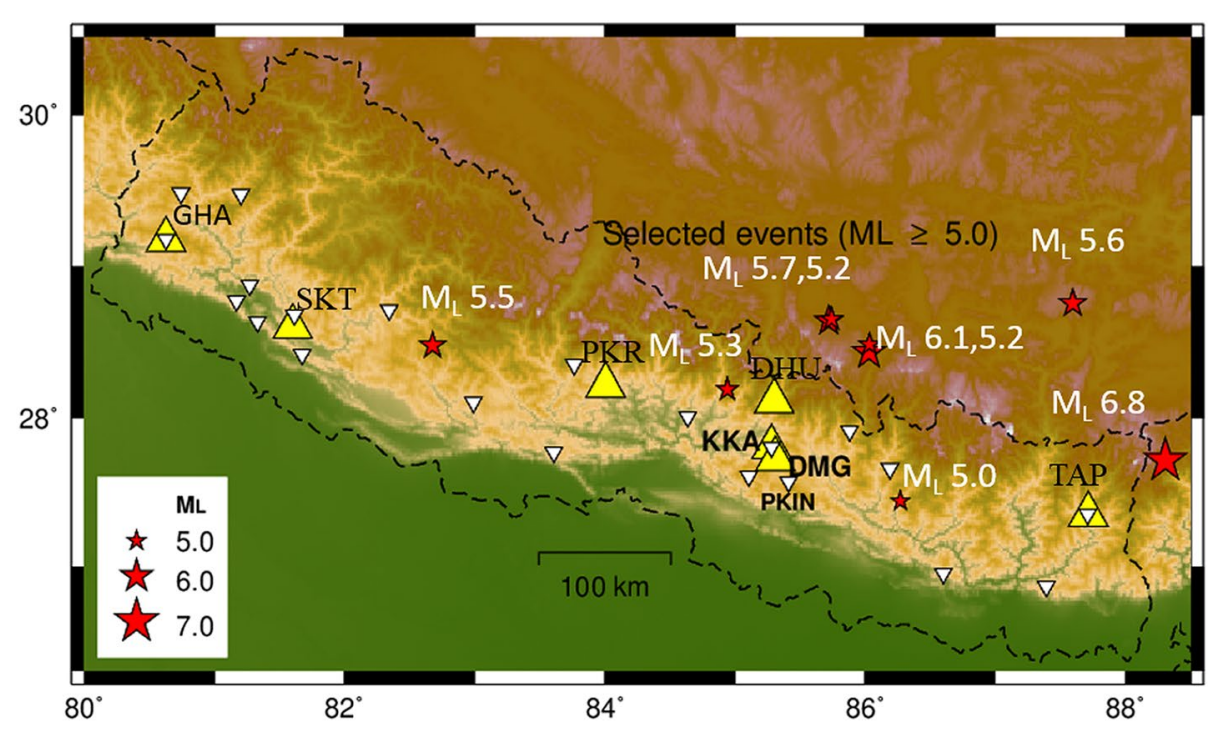

Fig. 2 Location of stations and earthquakes used in the analysis. The two yellow triangles designate KKA, DMG, and one white triangle PKIN. Red stars indicate epicenters of earthquakes used with corresponding magnitudes (Data Source: NSC)

Table 2 Instruments and site details

\begin{tabular}{|c|c|c|c|c|c|c|c|}
\hline $\begin{array}{l}\text { Station } \\
\text { code }\end{array}$ & Type of instrument & $\begin{array}{l}\text { Sampling } \\
\text { rate }(\mathrm{Hz})\end{array}$ & Latitude $\left({ }^{\circ}\right)$ & Longitude $\left({ }^{\circ}\right)$ & Altitude (m) & Geology & Remarks \\
\hline PKIN & $\begin{array}{l}\mathrm{ZM}, \mathrm{HM}-500(1 \mathrm{~Hz} \\
h=0.7) \text { velocity } \\
\text { seismograph }\end{array}$ & 50 & 27.57 & 85.39 & 2320 & $\begin{array}{l}\text { Rocks of Phulchauki Group } \\
\text { dominated by hematite } \\
\text { in Phulchauki tunnel }\end{array}$ & $\begin{array}{l}\sim 15 \mathrm{~km} \text { southeast of } \\
\text { Kathmandu }\end{array}$ \\
\hline DMG & $\begin{array}{l}\text { GeoSIG-AC } 23 \\
\text { Accelerograph } \\
\text { GeoSIG-GSR24 } \\
\text { digitizer }\end{array}$ & 200 & 27.72 & 85.31 & 1340 & Lacustrine deposit & $\begin{array}{l}\text { Central part of } \\
\text { Kathmandu }\end{array}$ \\
\hline KKA & $\begin{array}{l}\text { GeoSIG-AC } 23 \\
\text { Accelerograph } \\
\text { GeoSIG-GSR24 } \\
\text { digitizer }\end{array}$ & 200 & 27.80 & 85.27 & 2043 & Granite and gneiss rock & $\begin{array}{l}\sim 10 \mathrm{~km} \text { northwest of } \\
\text { Kathmandu }\end{array}$ \\
\hline
\end{tabular}

mass-spring system (i.e., velocity transducer of the natural frequency $4.5 \mathrm{~Hz}$ ) with electronic corrector that overdamps the geophone by applying a voltage with opposite polarity over the geophone and then the output response will be flat and proportional to the acceleration in the frequency range from 0.1 to $100 \mathrm{~Hz}$, and an amplifier is applied to this voltage difference to regulate the gain (GeoSIG Ltd. 2015). Therefore, for these two accelerometric stations, an attention is required on $S / N$ for very small amplitude signal at the low-frequency range. However, a quantitative discussion related to PKIN is possible within the target frequency range of this study, i.e., over $0.5 \mathrm{~Hz}$ and also the consideration is possible on the relation of DMG with KKA over $0.3 \mathrm{~Hz}$ as explained below.

The second largest earthquake, No. 8, was used as an example in order to explain the data processing using the software ViewWave (Kashima 2009). The accelerograms of Earthquake No. 8 (Table 1) at KKA, DMG and PKIN stations are shown in Fig. 3a-c, respectively. Particularly, those shown in Fig. 3c were obtained by the simple differentiation of the original velocity seismograms, but the instrumental correction was not yet applied. A time window of the $20 \mathrm{~s}$ was chosen from the start time written in the caption of Fig. 4a. The prerequisite for FFT (removal of DC trend, cosine taper and zero padding) was applied, and Fourier amplitude spectra were calculated and smoothed using the Parzen's window of bandwidth $0.2 \mathrm{~Hz}$.

The thing to be considered in this study is not the individual behavior of $\mathrm{SH}$ - and $\mathrm{SV}$-waves, but that of the entire S-waves. The displacement particle motions without clear polarity and also the similarity of the Fourier Amplitude of the two horizontal components (Fig. 4a, $\mathrm{b}$, respectively) suggest an isotropic feature of $\mathrm{S}$-waves. 

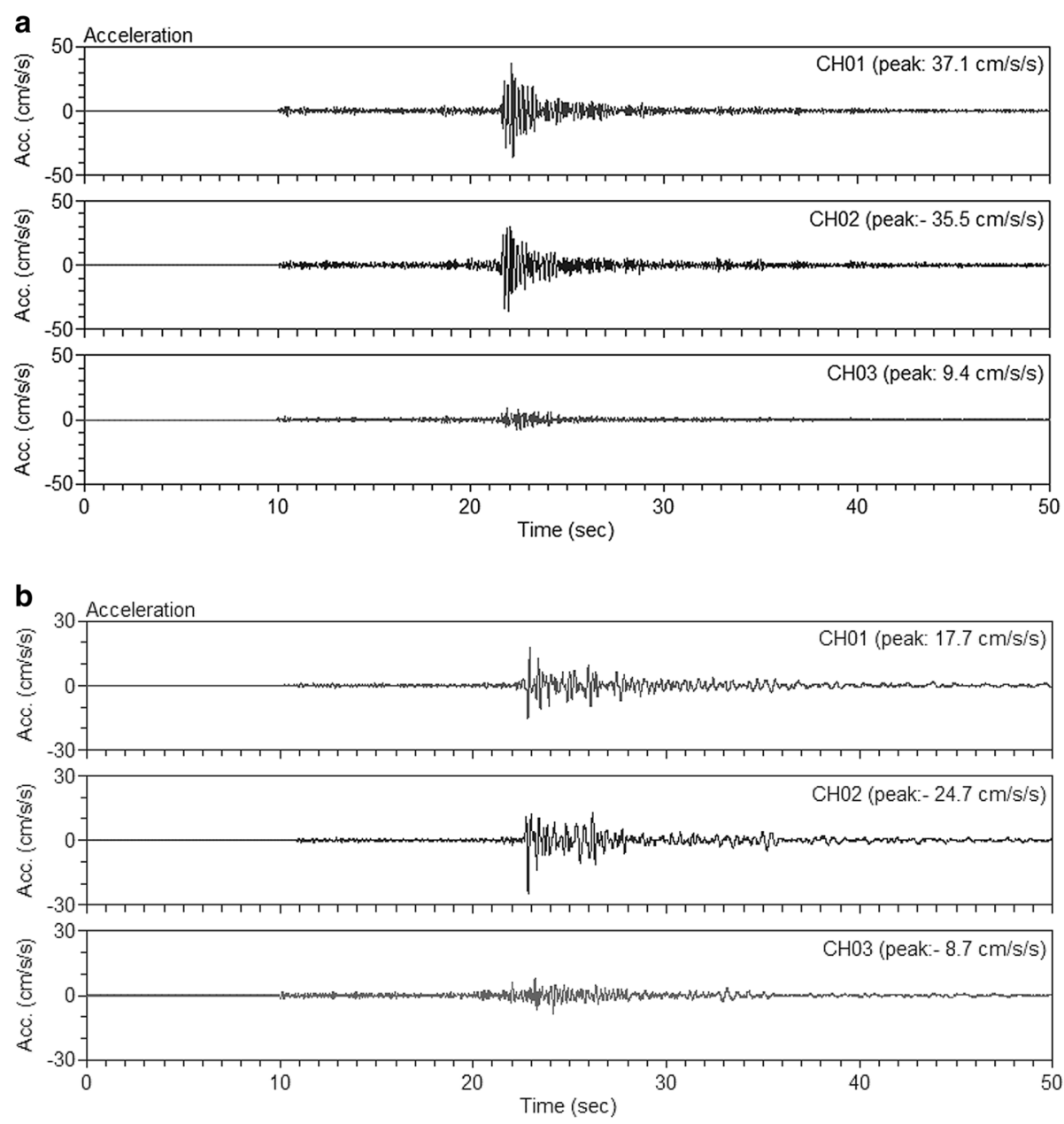

C

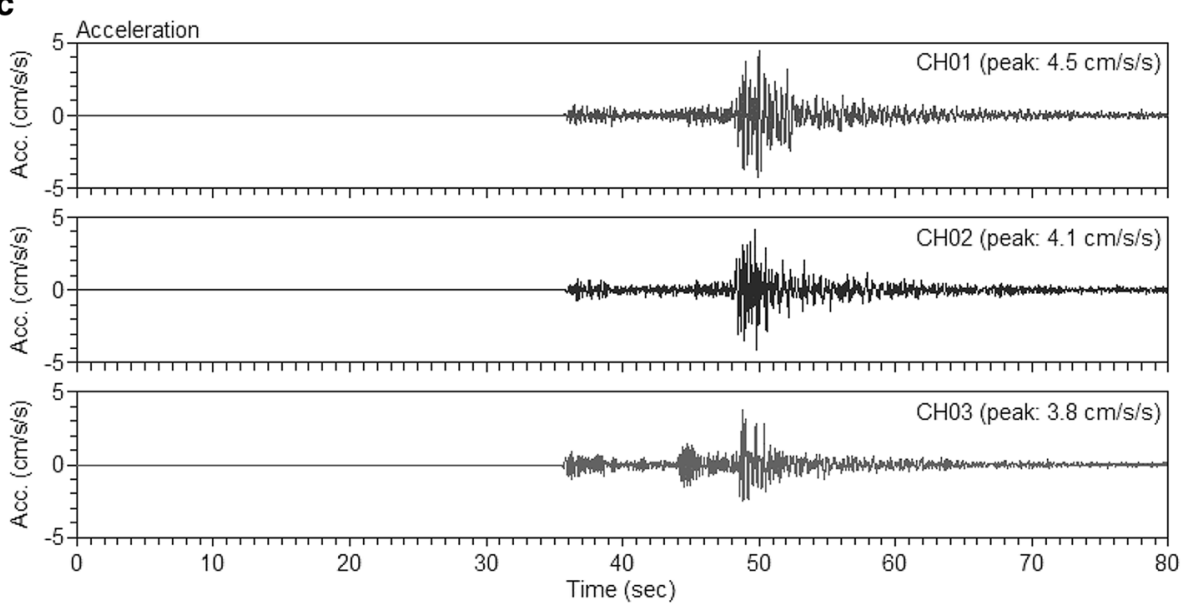

Fig. 3 Accelerograms of the earthquake No. 8 in Table 1 recorded at a KKA, b DMG and $\mathbf{c}$ PKIN stations. The last one was obtained by the simple differentiation of the original velocity seismograms, but without instrumental correction

Therefore, two horizontal components were combined into their Euclidian mean, i.e., the square root of the sum of the squares of NS and EW components (Fig. 5).
Then, an instrumental correction was done for the PKIN records only in the frequency domain. The broken and solid curves in Fig. 5c show those before and after 

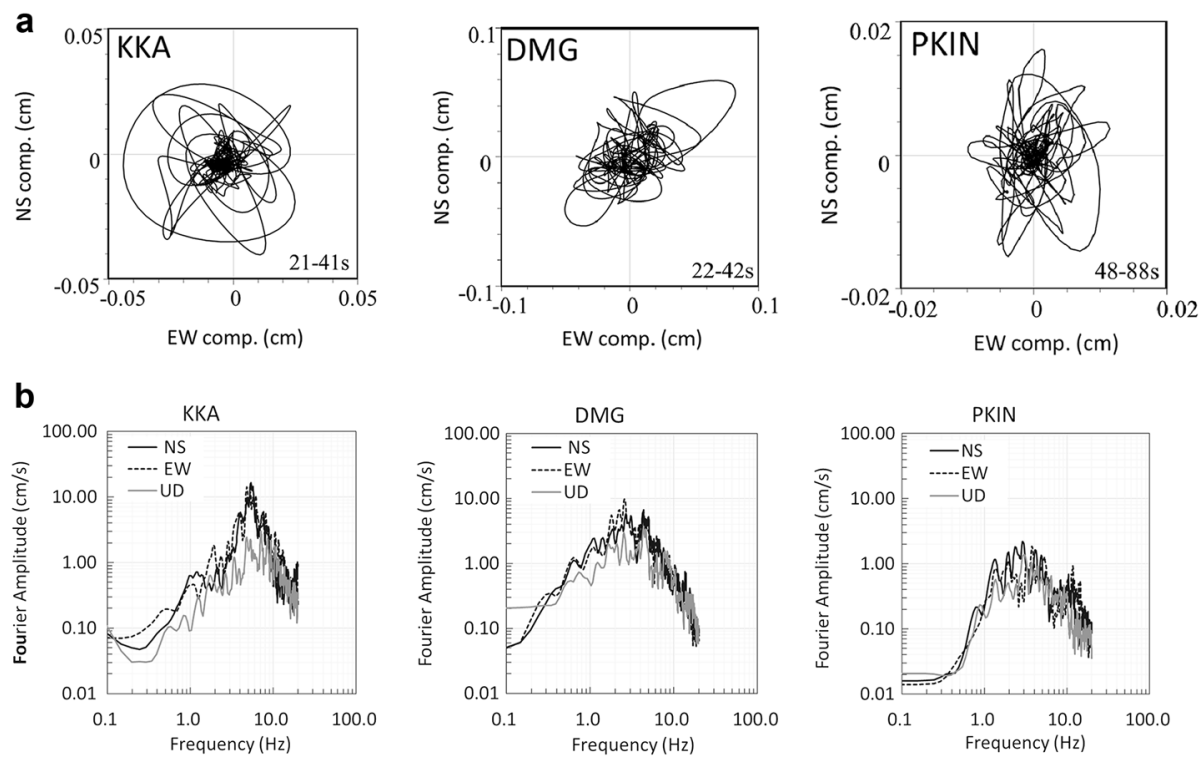

Fig. 4 Accelerograms of the earthquake No. 8 in Table 1 recorded at a displacement particle motions on horizontal plane. Low-cut filter is applied at $0.5 \mathrm{~Hz}$ to prevent the influence of noise, $\mathbf{b}$ the corresponding Fourier amplitude spectra of three components calculated using the time window of duration $20 \mathrm{~s}$ from 21, 22 and $46 \mathrm{~s}$ of the records of KKA, DMG and PKIN

the instrumental correction, respectively, and the gray curve shows the normalized instrumental response that is used for the instrumental correction. Hereafter, the name PKIN_Cor is used for the signals obtained at PKIN but after conversion to acceleration and removal of the instrumental response.

The strange behavior of the solid curve of Fig. $5 \mathrm{c}$ in the frequency range below $0.5 \mathrm{~Hz}$ is interpreted as the noise dominant in this range that was amplified by the instrumental correction, i.e., division by the instrumental response. The flat part of the broken curve at the same frequency range shows the noise level. This clearly shows that any discussion based on the spectral ratios
DMG/PKIN_Cor or KKA/PKIN_Cor in the frequency range below $0.5 \mathrm{~Hz}$ was not considered relevant and shall be excluded from the analysis. Similar flat parts are observed below $0.2 \mathrm{~Hz}$ in Fig. $5 \mathrm{a}$ and below $0.3 \mathrm{~Hz}$ in Fig. 5b. This implies that any discussion on the spectral ratio DMG/KKA cannot be fully reliable in the frequency range below $0.3 \mathrm{~Hz}$.

Finally, the Fourier amplitude spectra at the site of interest were divided by that of the reference sites to calculate the spectral ratio: DMG/KKA, DMG/PKIN_Cor and KKA/PKIN_Cor for earthquake No. 8 as shown in Fig. 6a-c, respectively. All three curves do not asymptote to the unity at low frequency due to the effect of the noise
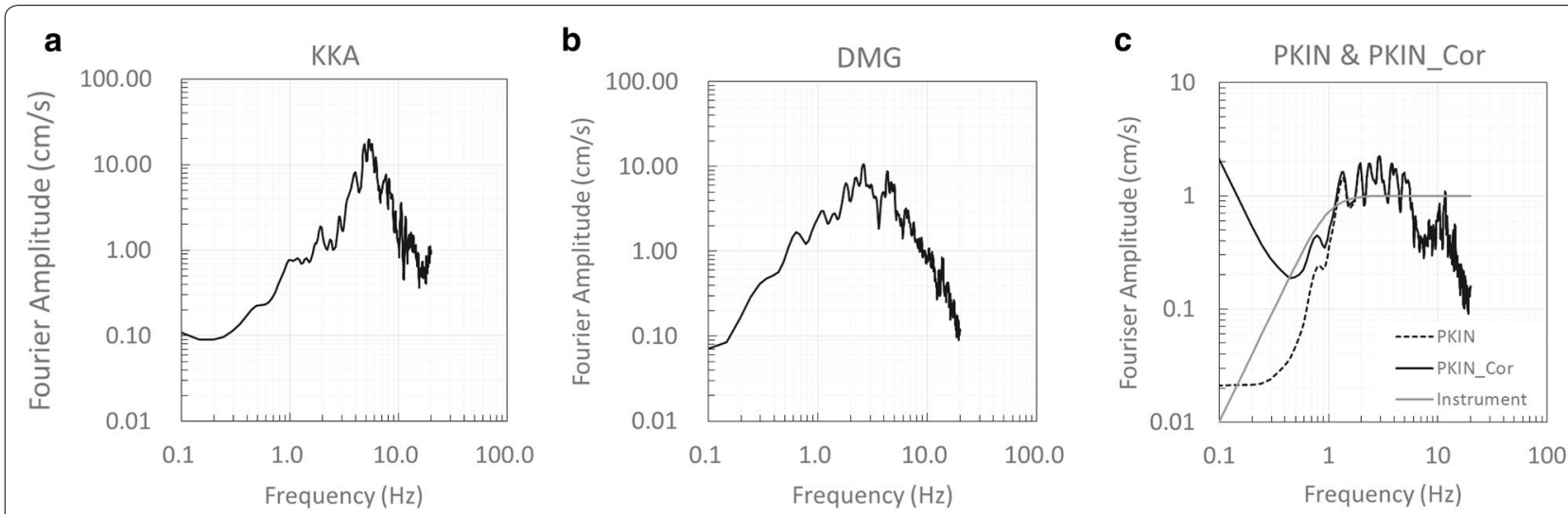

Fig. 5 Fourier amplitude spectra of the horizontal component (Euclidian mean of NS and EW components) of the event No. 8 in Table 1 at a KKA b DMG and c PKIN (dotted curve before the instrumental correction), PKIN_Cor (solid curve after the instrumental correction) and the instrumental response used for correction (gray curve) 
dominating the records of KKA, DMG and PKIN_Cor in the frequency range below $0.2,0.3$ and $0.5 \mathrm{~Hz}$, respectively. Namely, the noise makes the denominator spectra too big in the mentioned frequency ranges.

The same procedure was applied for other earthquakes' records. Finally, all available spectral ratios were plotted together, and their combined trend was analyzed and interpreted in the next section.

In order to take the elongation of S-wave trains during the propagation via long distance and also their difference depending on the magnitude into account, different values of the duration of the time window used to calculate FFT were used: $10 \mathrm{~s}$ for the earthquakes No. 2 and No. 9; $20 \mathrm{~s}$ for No. 3, No. 5, No. 6 and No. 8; 40 s for No. 4 and No. 7. Due to the setting of post-event time window the captured S-waves parts are shorter than $10 \mathrm{~s}$ for No. 1: $7 \mathrm{~s}$ for DMG; $8 \mathrm{~s}$ for KKA; and $10 \mathrm{~s}$ for PKIN. Number of samples for FFT was regulated by padding zeros after the records extracted using these time windows up to the bigger and closest integer that is a power of 2. Besides PKIN records are saturated during No. 4 and partly lost during No. 6 and No. 7 due to trouble of data acquisition system. Therefore, these three events are not used in discussion below.

For the sake of convenience, three frequency ranges were set as follows:

Range 1: lower than about $0.5 \mathrm{~Hz}$, Range 2: from about 0.5 to about $4 \mathrm{~Hz}$ and Range 3: from about 4 to $10 \mathrm{~Hz}$ and higher.

\section{Results}

The observations for the representative earthquake in the previous section can also be seen even for other events. The spectral ratio curves of all records used for DMG/ KKA, DMG/PKIN_Cor and KKA/PKIN_Cor are plotted in Fig. $7 \mathrm{a}-\mathrm{c}$, respectively. For most of the earthquakes, the ratios show similar trends.
The most notable one is the non-flat feature of the spectral ratio DMG/KKA. In Range 2, all curves are between the unity and 10, whereas in Range 3 below the unity. Namely, a rock site KKA has more amplification than DMG at the center of valley in Range 3, consistently with Bhattarai et al. (2011). This is supported by the spectral ratio DMG/PKIN_Cor in Fig. 7b that a drastic contrast in Range 2 and Range 3, and also by the observation of Fig. 7c, where the spectral ratio KKA/PKIN_Cor takes values around the unity in Range 2 and over 10 up to 25 in Range 3. Thus, it was confirmed that KKA has its own particular site response at Range 3. However, its mechanism is left unknown.

On the other hand, DMG/PKIN_Cor shows amplification around 4 or 5 in Range 2 and in Range 3 with narrow peaks and troughs. All the signals converged toward unity at higher frequencies above $10 \mathrm{~Hz}$. The sharp peak exceeding ten in Range 3 is particular only to earthquake No. 9. This clearly shows the site amplification at DMG is, at maximum, ten times higher than that of the newly created reference site PKIN.

Additionally, it was clearly observed that for the largest earthquake No. 4 exhibited a significant peak at 0.3 and also $0.6 \mathrm{~Hz}$ in Fig. 7a.

\section{Conclusions}

This study aimed to resolve an issue discovered in a previous study by Bhattarai et al. (2011) and to propose a better reference site for the investigation of site effect in and around the Kathmandu valley. The problem was that in the frequency range $4-10 \mathrm{~Hz}$ there was significant amplification at the rock site KKA in comparison with the soil-site DMG.

This anomaly was rechecked using the digital acceleration data of nine earthquakes obtained at these stations and also velocity seismogram of another rock site PKIN on the southern slope of Phulchauki Hill. The anomaly

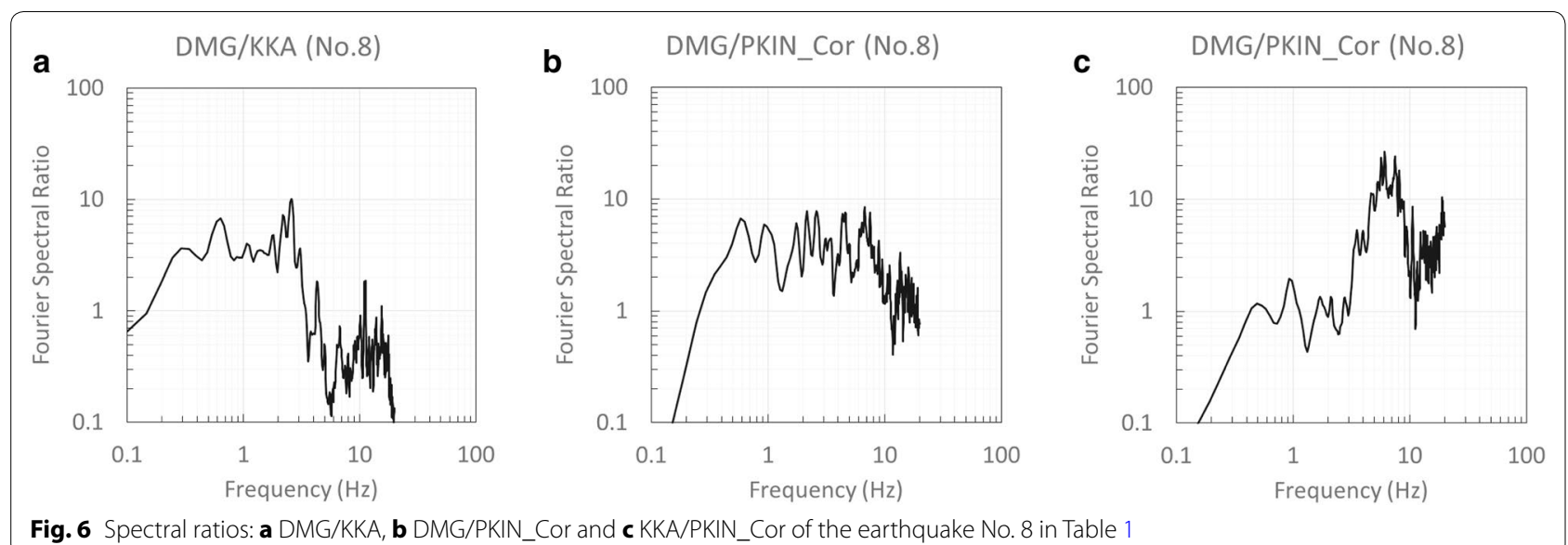

Fig. 6 Spectral ratios: a DMG/KKA, b DMG/PKIN_Cor and $\mathbf{c}$ KKA/PKIN_Cor of the earthquake No. 8 in Table 1 

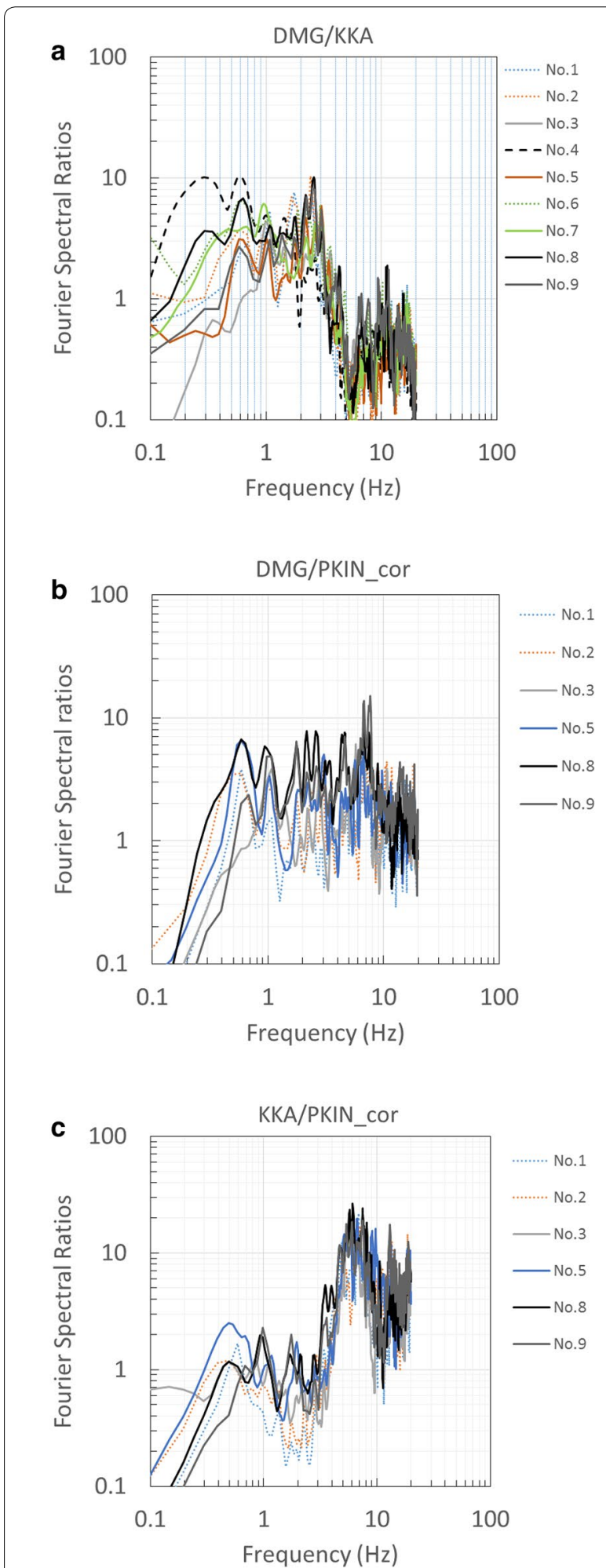

Fig. 7 a DMG/KKA, b MG/PKIN_Cor and cKKA/PKIN_Cor for all available records among the nine earthquakes in Table 1 reappeared for all of the analyzed earthquake records, and the amplification of KKA in comparison with DMG was confirmed. It was also confirmed using the spectral ratio of the ground motions of DMG to those of PKIN for the same earthquakes that the DMG site has amplification ranging from 1 to at most 10 times in the frequency range of $0.5-10 \mathrm{~Hz}$. On the other hand, the spectral ratios of KKA compared to PKIN showed that the KKA site has amplification in the frequency range $4-10 \mathrm{~Hz}$, with a peak value at most 10 . This means that site amplification in and around the Kathmandu valley that is estimated by spectral ratios with reference to KKA will be underestimated in the frequency range from 4 to $10 \mathrm{~Hz}$. The mechanism or reason of the amplification of seismic waves in this frequency range at KKA is left unknown. Further studies, e.g., parallel measurement of ambient noise and/or geophysical exploration are needed. In the frequency range higher than $1 \mathrm{~Hz}$, the mentioned data show the amplification at DMG site, but it is confirmed only for linear response range.

Additionally, amplification due to thick sediment in the valley has been suggested by the spectral ratio of DMG compared to KKA using the records of the 2011/09/18 Taplejung-Sikkim earthquake (NSC-DMG, $M_{\mathrm{L}}=6.8$ ). In the frequency range lower than $0.5 \mathrm{~Hz}$, the power of the used records DMG and KKA was not enough to reveal it clearly. Only this $M_{\mathrm{L}} 6.8$ earthquake has power there and the long period response is observed, but its reliability does not seem enough due to the poor $S / N$ in the frequency range lower than $0.3 \mathrm{~Hz}$ in DMG and KKA. A drastic site effect in the frequency range lower than $0.5 \mathrm{~Hz}$ has been shown during the 2015 Gorkha, Nepal earthquake (Bhattarai et al. 2015), not only in DMG but also in other stations (Takai et al. 2016; Kubo et al. 2016). However, further studies on additional strong motion records, among them on records of the main shock and aftershocks of the 2015 Gorkha earthquake, will be required to understand and quantify its effect.

Based on the analysis and interpretation in this paper, we propose that the station PKIN should be considered as a reliable reference site for the estimation of seismic hazards at different sites in and around the Kathmandu valley. An accelerograph has been installed newly at the station PKIN in May 2015, after the 2015 Gorkha, Nepal earthquake.

\section{Authors' contributions}

MB processed and interpreted the seismic data and wrote the manuscript. LB and $\mathrm{BH}$ helped for the earthquakes selection and preliminary interpretation. LBA and UPG helped for the database management and field operations. TY and $\mathrm{TH}$ supervised the data processing and interpretation. All authors edited the article. All authors read and approved the final manuscript. 


\section{Author details}

${ }^{1}$ National Seismological Center, Department of Mines and Geology, Kathmandu, Nepal. ${ }^{2}$ CEA, DAM, DIF, 91297 Arpajon, France. ${ }^{3}$ International Institute of Seismology and Earthquake Engineering, Building Research Institute, Tsukuba, Japan.

\section{Acknowledgements}

I would like to thank our Director General Mr. Sarbjit Prasad Mahato and Deputy Director General Dr. Soma Nath Sapkota for allowing me to publish this manuscript. I am very thankful to Dr. T. Kashima (Senior Research Engineer, IISEE/BRI) for allowing me to use the software he developed and guiding me through it. I am also thankful to Dr. T. Hara (Chief Research Scientist, IISEE), for his valuable comments and suggestions. I am very much thankful to my colleague at NSC Mr. Bharat Prasad Koirala for his support and encourage during the preparation of this manuscript. I would also like to thank DASE, CEA for technical support to install and maintain the stations KKA, DMG and PKIN used in this study. We appreciate two anonymous reviewers for their invaluable comments. This study was mainly conducted during the stay of the first author M. Bhattarai in Building Research Institute (BRI), Japan from October 2013 to September 2014 for Master Program jointly held by BRI and National Graduate Institute for Policy Studies (GRIPS), before the 2015 Gorkha, Nepal earthquake.

\section{Received: 13 October 2015 Accepted: 26 April 2016}

Published online: 17 May 2016

\section{References}

Bhattarai M, Gautam U, Pandey R, Bollinger L, Hernandez B, Boutin V (2011) Capturing first records at the Nepal NSC accelerometric network. J Nepal Geol Soc 43:15-22

Bhattarai M, Adhikari LB, Gautam UP, Laurendeau A, Labonne C, HosteColomer R, Sèbe O, Hernandez B (2015) Overview of the large April 25th Gorkha, Nepal earthquake from accelerometric prospective. Seismol Res Lett 86:40-48

Borcherdt RD (1970) Effect of geology in ground motion near San Francisco bay. Bull Seismol Soc Am 60:29-61

Dixit AM, Ringler AT, Sumy DF, Cochran ES, Hough SE, Martin SS, Gibbons S, Luetgert JH, Galetzka J, Shrestha SN, Rajaure S, McNamara DE (2015) Strong-motion observations of the M 7.8 Gorkha, Nepal, earthquake sequence and development of the N-SHAKE strong-motion network. Seismol Res Lett 86:1533-1539

GeoSIG Ltd. (2015) AC-23 accelerometer manual. http://www.geosig.com. Accessed 18 Dec 2015
Japan International Cooperation Agency (2002) the study on earthquake disaster mitigation in the Kathmandu Valley Kingdom of Nepal, vols I-III. Japan International Cooperation Agency (JICA) and Ministry of Home Affairs His Majesty's Government of Nepal, Nippon Koei Co., Ltd., Oyo Corporation

Kashima T (2009) ViewWave software (version 1.56). http://www.smo.kenken. go.jp/ kashima/viewwave/. Accessed 18 Sep 2015

Kobayashi T, Morishita Y, Yarai H (2015) Detailed crustal deformation and fault rupture of the 2015 Gorkha earthquake, Nepal, revealed from ScanSARbased interferograms of ALOS-2. Earth Planets Space 67:201

Kubo H, Dhakal Y, Suzuki W, Kunugi T, Aoi S, Fujiwara H (2016) Estimation of the source process of the 2015 Gorkha, Nepal, earthquake and simulation of long-period ground motions in the Kathmandu basin using a onedimensional basin structure model. Earth Planets Space 68:16

Moribayasi S, Maruo Y (1980) Basement topography of the Kathmandu Valley, Nepal - an application of gravitational method to the survey of a tectonic basin in the Himalayas. J J.pn Soc Eng Geol 21:30-37

Nakamura Y (1989) A method for dynamic characteristics estimation of subsurface using microtremor on the ground surface. Q Rep Railw Tech Res Inst 30:25-33

National Seismological Centre (NSC). http://www.seismonepal.gov.np/. Accessed 18 Sep 2015

Paudyal YR, Bhandary NP, Yatabe R (2012) Seismic microzonation of densely populated area of Kathmandu Valley of Nepal using microtremor observations. J Earthq Eng 16:1208-1229

Piya BK (2004) Generation of a geological data base for the liquefaction hazard assessment in Kathmandu valley. M.Sc. thesis, International Institute for Geo-Information Science and Earth Observation, Enschede, The Netherlands

Rana M, Braham G, Sumsher JB (1935) Nepalko Bhukampa (the great earthquake of Nepal), 2nd edn. Jorganesh Press, Kathmandu (in Nepali)

Roy SC, Dunn JA, Auden JA, Ghosh AMN (1939) The Bihar-Nepal earthquake of 1934. Mem Geol Surv India 73:391

Sakai H (2001) Stratigraphic division and sedimentary facies of the Kathmandu basin sediments. J Nepal Geol Soc 25:19-32

Sakai H, Sakai H, Yahagi W, Fujii R, Hayashi T, Upreti BN (2006) Pleistocene rapid uplift of the Himalayan frontal ranges recorded in the Kathmandu and Siwalik basins. Paleogeogr Paleoclimatol Paleoecol 241:16-27

Steidl H, Tumarkin G, Archuleta j (1996) What is a reference site? Bull Seismol Soc Am 86:33-48

Takai N, Shigefuji M, Rajaure S, Bijukchhen S, Ichiyanagi M, Dhital M, Sasatani T (2016) Strong ground motion in the Kathmandu Valley during the 2015 Gorkha, Nepal, earthquake. Earth Planets Space 68:10

Yoshida M, Igarashi Y (1984) Neogene-Quaternary Lacustrine sediments in Kathmandu Valley. J Nepal Geol Soc 4 (special issue):73-100

\section{Submit your manuscript to a SpringerOpen ${ }^{\circ}$ journal and benefit from:}

- Convenient online submission

- Rigorous peer review

- Immediate publication on acceptance

- Open access: articles freely available online

- High visibility within the field

- Retaining the copyright to your article 